\title{
A Modified Fama and French (1993) Three-factor Asset Pricing Model: Evidence from the UK Equity Market
}

\author{
Mohammad Q. M. AL-Momani ${ }^{1}$ \\ ${ }^{1}$ Assistant Professor at the Department of Finance \& Banking, Faculty of Economics \& Administrative Sciences, the \\ Hashemite University, Zarqa, Jordan. \\ Correspondence: Mohammad Qasim Mohammad AL-Momani, the Department of Finance \& Banking, Faculty of \\ Economics \& Administrative Sciences, the Hashemite University, P.O. Box 330127, Zarqa, Jordan.
}

Received:March 15, 2016

Accepted:March 31, 2016

Available online: April 5, 2016

doi:10.11114/aef.v3i3.1463

URL: http://dx.doi.org/10.11114/aef.v3i3.1463

\begin{abstract}
The objective of this study is to examine the modified Fama and French (1993) three-factor asset pricing model, suggested by Cremers et al. (2012), in the UK equity market, over the period from October 1980 to June 2015. The article follows the correct Lewellen et al. (2010) framework for evaluating asset pricing models. In contrast to Michou et al. (2007) and Gregory et al. (2013), the results suggest the use of the modified Fama and French (1993) three-factor asset pricing model in practical applications that require the estimation of expected returns in the UK equity market. The results are robust using the same sample period in Gregory et al. (2013). Overall, the result suggests to follow the correct Lewellen et al. (2010) framework for evaluating asset pricing models in pricing the UK equity market returns.
\end{abstract}

Keywords: Asset pricing, Modified Fama and French (1993) three-factor model ; Cross-sectional; UK

JEL Codes: G10; G12; G14

\section{Introduction}

In response to the empirical evidence of the poor performance of the Sharpe (1964) - Lintner (1965) Capital Asset Pricing Model (CAPM) and the Breeden (1979) Intertemporal Asset Pricing Model (ICAPM) in explaining the cross-section of average returns on US common stocks, Fama and French (1993) identify three risk factors that explain the cross-sectional variation in the US stock market returns, over the period from July 1963 to December 1991. These are the market factor (MKT), the size factor (SMB), and the value factor (HML). MKT is the return to market portfolio, SMB is the monthly difference between the average returns on the three small-stocks portfolios and the average returns on the three big-stocks portfolios, and HML is the monthly difference between the average returns on the two high book-to-market portfolios and the average returns on the two low book-to-market portfolios. The two components they use in constructing each of the SMB and the HML are equally-weighted returns. Several studies dealing with UK equity data use the Fama and French (1993) three-factor model, for instance, Miles and Timmerman (1996) use it to study the properties of UK expected returns, Liu et al. (1999) evaluate the profitability of momentum strategies in the UK using it, and Gregory et al. (2001) investigate whether the profitability of value strategies in the UK can be explained using the three factor model. ${ }^{\mathrm{i}}$ Furthermore, Hussain et al. (2002) employ it to test for the existence of the size effect in the UK stock market whilst replicating Fama and French (1996). Another study by AL-Horani et al. (2003) suggests that a modification to the three factor model that take into account the Research and Development (RD) activity significantly improve the explanatory power of the three factor model.

Recently, Michou et al. (2007) use the SMB and HML constructed in the aforementioned studies to examine the robustness of the Fama and French (1993) three-factor asset pricing model in the UK equity market, for the period from

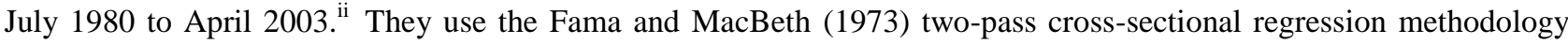
and test the model on portfolios sorted on industry as suggested by Lo and MacKinlay (1990) and on portfolios sorted on size and book-to-market plus industry portfolios suggested by Lewellen et al. (2010), and find that regardless of the method used in constructing the SMB and HML, none lead to a priced risk-factors that reflect the size and book-to-market effects in the UK equity market. More recently, Cremers et al. (2012) suggest modifications to the formation of the SMB and HML factors in Fama and French (1993) to mitigate the non-zero performance of passive indexes including the S\&P 500 and Russell 2000 benchmarks. ${ }^{i i i}$ They use data that cover the period from 1980 to 2005, 
and find that the modified Fama and French (1993) three-factor asset pricing model performs better than the traditional Fama and French (1993) three-factor model in providing lower tracking error volatility and in assigning zero performance for size/value portfolios. Furthermore, Lewellen et al (2010) suggest not only expanding the test assets beyond the size and book-to-market sorted portfolios using industry or volatility sorted portfolios, but also imposing theoretical restrictions on the zero-beta rate and the risk-premia and using the Generalized Least Squares (GLS) approach of the Fama and MacBeth (1973) cross-sectional regression methodology instead of the Ordinary Least Squares (OLS), the Weighted Least Square (WLS), and the Stochastic Discount Factor/Generalized Method of Moments of Hansen (1982) methods. ${ }^{\text {iv }}$ They apply their suggestions to examine several prominent asset-pricing models with macroeconomic and financial factors, and find, based on a set of simulations, evidence that these models do not work as originally advertised compared to the results from the CAPM, the unconditional consumption CAPM , and the Fama and French (1993) three-factor asset pricing benchmark models. ${ }^{v}$

These findings motivate this article to examine the modified Fama and French (1993) three-factor asset pricing model, suggested by Cremers et al. (2012), in the UK equity market.It follows the correct Lewellen et al. (2010) framework for examining asset pricing models. Therefore, the model is required to price the cross-sectional variation in the excess returns on the 25 portfolios sorted on size and book-to-market plus 25 portfolios sorted on volatility, as suggested by Lewellen et al. (2010), in excess of the one-month UK Treasury bill rate, for the period from October 1980 to June 2015. ${ }^{\text {vi }}$ It imposes the theoretical restrictions that the zero-beta rate is equal to the risk-free rate and the risk-premia is equal to the factor expected excess returns, as recommended by Lewellen et al. (2010). To avoid the problems associated with the cross-sectional regressions tests discussed in Shanken and Zhou (2007) and Lewellen et al. (2010), the study use the GLS approach of the Fama and MacBeth (1973) two-pass cross-sectional regression methodology, as suggested by Lewellen et al. (2010). ${ }^{\text {vii }}$

This study extends the literature on evaluating the Fama and French (1993) three-factor asset pricing model in the UK equity market. In contrast to Michou et al. (2007), the study finds that a modified Fama and French (1993) three-factor asset pricing model, suggested by Cremers et al. (2012), is able to explain the cross-sectional variation in the UK equity market excess returns.This is an out-of-sample evidence consistent with the Fama and French (1993) asset pricing theory.

A close paper to this study is Gregory et al. (2013) who examine alternative versions of asset pricing theories, including the modified Fama and French (1993) three-factor asset pricing model suggested by Cremers et al. (2012), in the UK equity market, over the period from October 1980 to December 2010. They claim they consider Lewellen et al. (2010) suggestions by testing the model on volatility sorted portfolios and imposing theoretical restrictions on the zero-beta rate and the risk-premia. They use the Fama and MacBeth (1973) two-pass cross-sectional methodology - using either an assumption of constant parameter estimates or rolling 60-monthly estimates of the parameters - and find, consistent with the findings in Michou et al. (2007), that the modified Fama and French (1993) three-factor asset pricing model, suggested by Cremers et al. (2012), is unable to explain the cross-sectional variation in the UK equity market excess returns. The results in this study show that Gregory et al. (2013) conclusion is incorrect as they didn't apply the correct Lewellen et al. (2010) framework for examining asset pricing models. Once this is done, the results suggest the use of the modified Fama and French (1993) three-factor model, suggested by Cremers et al. (2012), in practical applications that require the estimation of expected returns in the UK equity market.

As a robustness test, the study use the same sample period in Gregory et al. (2013). Hence, it considers a monthly sub-sample that ends in December 2010. The main finding that the modified Fama and French (1993) three-factor asset pricing model, suggested by Cremers et al. (2012), is able to explain the cross-sectional variation in the UK equity market is robust using this sub-sample period. Overall, the result suggest the use of the correct Lewellen et al. (2010) framework for evaluating asset pricing models in the UK equity market.

Up to my knowledge, this is the first study that applies the correct Lewellen et al. (2010) framework for evaluating asset pricing models in UK equity market. Therefore this research will be valuable to all interested parties, provides updated general results that can be used as a reference point in supporting academic purposes, investment professionals, and individual investors.

The study is organized as follows: Section 2 contains the methodology. Section 3 describes the data and provides summary statistics. Section 4 provides the empirical results and analysis. Section 5 is the robustness. Finally, Section 6 concludes.

\section{Methodology}

This article examines the modified version of the Fama and French (1993) three-factor asset pricing model suggested by Cremers et al. (2012). The model is expressed as

$$
R_{t}^{e i}=\alpha_{i}+b_{i, M K T} M K T_{t}+b_{i, S M B} S M B_{t}+b_{i, H M L} H M L_{t}+\varepsilon_{t}^{i},
$$


where, $R_{t}^{e i}$ is equal to the monthly excess return on portfolioiat time $t(t=1,2, \ldots, T$, and $T$ is the number of months). The study use the 25 portfolios sorted on size and book-to-market plus 25 portfolios sorted on Volatility as a UK test assets, as suggested by Lewellen et al. (2010). In addition to the market factor $(M K T)$, the article use the Fama and French (1993) size $(S M B)$ and value $(H M L)$ value-weighted risk-factors, as suggested by Cremers et al. (2012). $\alpha_{i}$ is the pricing error of portfolio $i$, and $b_{i, j}$ are the beta coefficients ( $j=M K T, S M B$, and $H M L$ respectively). $\varepsilon_{t}^{i}$ denotes the residuals. The model states that expected returns are linear in betas,

$$
E_{T}\left(R^{e i}\right)=\beta_{i}^{\prime} E_{T}(f)
$$

where, $E_{T}($.$) is the sample mean. f=[M K T, S M B, H M L] . \beta_{i}^{\prime}$ is the $K$-vector of the beta coefficient of portfolio $i . K$ is number of factors. Comparing the model in (2) with the expectation of the time-series regression in (1), it shows that the model has one and only one application to the data: all the regression intercepts $\alpha_{i}$ should be zero. Given this fact, Black, Jensen and Scholes (1972) and Fama and MacBeth (1973) suggest running the time-series regression in (1) for each of the test assets. The estimate of the factor risk premium is equal to the sample mean of the factors,

$$
\lambda_{T S}=E_{T}(f) .
$$

When testing the null hypothesis that all pricing errors are jointly equal to zero, the study use the GRS $F$-statistics of Gibbons et al. (1989). This is a finite-sample $F$ distribution assumes that errors $\varepsilon$ are normal as well as uncorrelated and homoskedastic. It is expressed as follows,

$$
\frac{T-N-K}{N}\left(1+E_{T}(f)^{\prime} \hat{\Omega}^{-1} E_{T}(f)\right)^{-1} \hat{\alpha}^{\prime} \hat{\Sigma}^{-1} \hat{\alpha} \sim F_{N, T-N-K},
$$

where, $N$ is the number of test assets, $E_{T}(f)$ is the sample mean of the factors, $\widehat{\Omega}=\frac{1}{T} \sum_{t=1}^{T}\left[f_{t}-E_{T}(f)\right]\left[f_{t}-E_{T}(f)\right]^{\prime}$ and $\widehat{\Sigma}=\frac{1}{T} \sum_{t=1}^{T} \hat{\varepsilon}_{t} \hat{\varepsilon}_{t}^{\prime}$.

In the second-pass, the article impose the theoretical restrictions that the zero-beta rate is equal to the risk-free rate and the risk premia is equal to the factor expected excess returns, as recommended by Lewellen et al. (2010), and estimates the factor risk premium $\lambda$ from a regression across the $N$ test portfolios of average excess returns on the betas,

$$
E_{T}\left(R_{i}^{e i}\right)=\beta_{i}^{\prime} \lambda+e_{i}
$$

where, $E_{T}\left(R_{i}^{e i}\right)$ is the average excess return of portfolio $i(i=1,2,3, \ldots, N) . \beta_{i}^{\prime}$ denotes the beta coefficients of portfolio $i$ obtained from the time-series regressions in (1). $e_{i}$ is the cross-sectional regression pricing errors. $\lambda$ is a vector of a risk-premia on the $K$-factors. Following Cochrane (2005), the study defines $\beta=\left[\beta_{1}^{\prime}, \beta_{2}^{\prime}, \ldots, \beta_{N}^{\prime}\right]^{\prime}, \varepsilon_{t}=$ $\left[\varepsilon_{t}^{1}, \varepsilon_{t}^{2}, \ldots, \varepsilon_{t}^{N}\right]^{\prime}, \mu_{R}=\left[R_{t}^{e 1}, R_{t}^{e 2}, \ldots, R_{t}^{e N}\right]$, and $e=\left[e_{1}, e_{2}, \ldots, e_{N}\right]$. The pricing error $e$ is given as,

$$
e=\mu_{R}-\beta \lambda \text {. }
$$

The estimated risk-premia is the solution of the following minimization problem,

$$
\hat{\lambda}=\operatorname{argmin}_{\widehat{\lambda}_{t}}\left(\mu_{R}-\beta \lambda\right)^{\prime} W\left(\mu_{R}-\beta \lambda\right)=\left(\beta^{\prime} W \beta\right)^{-1} \beta^{\prime} W \mu_{R} .
$$

To avoid the problems associated with the cross-sectional regression tests discussed in Shanken and Zhou (2007) and Lewellen et al. (2010), the article use the Generalized Least Squares (GLS) approach as suggested by Lewellen et al. (2010). The GLS uses $W=\hat{\Sigma}=\operatorname{cov}\left(\varepsilon_{t} \varepsilon_{t}^{\prime}\right)$, an $(N \times N)$ matrix denotes the estimated residuals covariance matrix.

To test the null hypothesis that the estimated factor risk-premia $\hat{\lambda}$ is statistically equal to zero, the study use the asymptotic distribution of $\hat{\lambda}$ developed by Shanken (1992) who show that the usual Fama-MacBeth variance for $\hat{\lambda}$ is augmented by an adjustment that corrects for the estimation error in betas from the time-series regression in (1) (errors-in-variables (EIV) problem). The variance of $\hat{\lambda}$ is given as

$$
\operatorname{var} \hat{\lambda}=\frac{1}{\pi}\left[\left(\beta^{\prime} \Sigma^{-1} \beta\right)^{-1}\left(1+\lambda^{\prime} \widehat{\Omega}^{-1} \lambda\right)+\widehat{\Omega}\right] \text {, }
$$

where $\Sigma=\operatorname{cov}\left(\varepsilon_{t} \varepsilon_{t}^{\prime}\right)$ is the variance-covariance matrix of the residuals and $\left(1+\lambda^{\prime} \widehat{\Omega}^{-1} \lambda\right)$ denotes the Shanken correction.Shanken (1992) $t$-ratio $t_{S h}$ is given as

$$
t_{S h}=T *\left(\lambda_{t} / \operatorname{cov}(\operatorname{diag} V(\hat{\lambda})) .\right.
$$

To examine the validity of the model, the article use the asymptotic $F$-statistics of Shanken (1985) to test the null hypothesis that the $N$ pricing errors are jointly equal to zero. The test is given as

$$
\frac{T-N-K}{N}\left(1+\lambda^{\prime} \widehat{\Omega}^{-1} \lambda\right)^{-1} e^{\prime} \widehat{\Sigma}^{-1} e \sim F_{N, T-N-K},
$$

\section{Data and Summary Statistics}

The test assets and factors are from Gregory et al. (2013) and cover the period from October 1980 to June 2015. The data are available on the website of Xfi Centre for Finance and Investment - University of Exeter. ${ }^{\text {viii }}$

The monthly value-weighted excess returns on the 25 portfolios sorted on size and book-to-market are constructed based on the intersections of 5 portfolios formed on size and 5 portfolios formed on the ratio of book equity to market equity. The 25 Volatility portfolios are formed based on the standard deviation of prior 12-month returns. The article use the return on the one-month UK Treasury bill rate as the risk-free rate. Table 1 reports the descriptive statistics for the 
test assets. The tendency within size portfolios is for excess returns to increase as book-to-market ratio increases, although the effect is not monotonic in all of the size portfolios. The general pattern appears to be for skewness to be more negative and kurtosis to be greater in the "growth" category than the "value" category within any size group, with the exceptions being kurtosis in the second smallest and medium size portfolios. Although the effect is not monotonic, the standard deviation of the portfolio returns increases as we move from low standard deviation portfolio ( $\left.\mathrm{SD}_{1}\right)$ to high standard deviation portfolio $\left(\mathrm{SD}_{25}\right)$. However, excess returns do not increase with standard deviation. For instance, $\mathrm{SD}_{25}$ has a standard deviation of $11.06 \%$ with the lowest mean excess returns of $0.22 \%$. This is not a violation of portfolio theory given that higher risk portfolios have an offsetting effect from lower correlations with other assets (Gregory et al., 2013). Finally, there is no general pattern for skewness and kurtosis.

The excess return on the market portfolio is equal to the excess return to the FTSE350 Index. ${ }^{\mathrm{ix}}$ Following Cremers et al. (2012), the study use the approach of value-weighting the six portfolios from which the Fama and French (1993) size $(S M B)$ and value $(H M L)$ factors are formed as follows,

$$
\begin{gathered}
S M B=\frac{\left[S L * V_{S L}\right]+\left[S M * V_{S M}\right]+\left[S H * V_{S H}\right]}{V_{S L}+V_{S M}+V_{S H}}-\frac{\left[B L * V_{B L}\right]+\left[B M * V_{B M}\right]+\left[B H * V_{B H}\right]}{V_{B L}+V_{B M}+V_{B H}}, \\
H M L=\frac{\left[S H * V_{S H}\right]+\left[B H * V_{B H}\right]}{V_{S H}+V_{B H}}-\frac{\left[S L * V_{S L}\right]+\left[B L * V_{B L}\right]}{V_{S L}+V_{B L}},
\end{gathered}
$$

where, "SL" is the small size-low book-to-market portfolio, "SM" is the small size-medium book-to-market portfolio, "SH" is the small size-high book-to-market portfolio, "BL" is the big size-low book-to-market portfolio, "BM" is the big size-medium book-to-market portfolio, "BH" is the big size-high book-to-market portfolio, and "Vxx" is the market capitalisation of a particular portfolio ( $\mathrm{xx}=\mathrm{SL}, \mathrm{SM}, \mathrm{SH}, \mathrm{BL}, \mathrm{BM}, \mathrm{BH})$.

Table 1. Summary statistics for the excess returns on the 25 value-weighted portfolios sorted on size and book-to-market plus 25 value-weighted portfolios sorted on volatility

\begin{tabular}{cccccccccccc}
\hline \multicolumn{1}{c}{ Mean (\%) } & \multicolumn{1}{c}{ Panel A } \\
\hline & Low & 2 & 3 & 4 & High & & Low & 2 & 3 & 4 & High \\
Small & 0.57 & 0.65 & 0.78 & 0.85 & 0.93 & Small & 6.26 & 5.46 & 5.12 & 5.18 & 5.10 \\
2 & 0.45 & 0.71 & 0.75 & 0.78 & 0.79 & 2 & 6.63 & 6.11 & 5.37 & 5.63 & 6.26 \\
3 & 0.50 & 0.46 & 0.66 & 0.71 & 1.07 & 3 & 6.67 & 5.92 & 5.78 & 5.97 & 6.34 \\
4 & 0.61 & 0.53 & 0.78 & 0.75 & 0.90 & 4 & 6.02 & 5.62 & 5.49 & 6.27 & 6.48 \\
Big & 0.42 & 0.36 & 0.53 & 0.65 & 0.71 & Big & 4.79 & 4.81 & 5.23 & 5.39 & 5.44 \\
& & \multicolumn{1}{c}{ Skew } & & & & & Kurt & & \\
& Low & 2 & 3 & 4 & High & & Low & 2 & 3 & 4 & High \\
Small & -0.62 & -0.36 & -0.30 & -0.52 & -0.22 & Small & 6.00 & 4.93 & 5.83 & 6.33 & 6.92 \\
2 & -0.47 & -0.87 & -0.50 & -0.35 & 0.07 & 2 & 5.91 & 5.43 & 5.21 & 4.94 & 8.29 \\
3 & -1.05 & -0.64 & -1.19 & -0.44 & -0.22 & 3 & 8.82 & 5.98 & 8.30 & 5.20 & 6.25 \\
4 & -0.50 & -0.78 & -0.71 & -0.46 & -0.41 & 4 & 8.41 & 7.86 & 5.87 & 5.35 & 5.99 \\
Big & -1.17 & -0.96 & -0.65 & -0.77 & -0.40 & Big & 10.18 & 6.90 & 5.37 & 6.68 & 4.72 \\
& & \multicolumn{1}{c}{ Min $(\%)$} & & & & & Max $(\%)$ & & \\
& Low & 2 & 3 & 4 & High & & Low & 2 & 3 & 4 & High \\
Small & -27.91 & -25.17 & -21.73 & -23.35 & -23.53 & Small & 25.51 & 18.12 & 24.91 & 23.76 & 28.03 \\
2 & -28.51 & -28.07 & -23.69 & -25.66 & -28.57 & 2 & 29.56 & 20.32 & 22.01 & 18.80 & 35.75 \\
3 & -34.18 & -29.86 & -33.88 & -27.02 & -27.81 & 3 & 32.95 & 23.78 & 16.09 & 21.93 & 32.42 \\
4 & -33.80 & -32.55 & -28.42 & -28.09 & -32.87 & 4 & 31.90 & 25.63 & 17.61 & 27.71 & 28.08 \\
Big & -35.22 & -29.62 & -25.11 & -31.64 & -21.19 & Big & 12.75 & 14.10 & 15.31 & 16.13 & 21.15 \\
\hline & & & & & & & & & & &
\end{tabular}




\begin{tabular}{|c|c|c|c|c|c|c|c|c|c|c|c|c|c|}
\hline \multicolumn{14}{|c|}{ Panel B } \\
\hline Portfolio & $\mathrm{SD}_{1}$ & $\mathrm{SD}_{2}$ & $\mathrm{SD}_{3}$ & $\mathrm{SD}_{4}$ & SD5 & $\mathrm{SD}_{6}$ & $\mathrm{SD}_{7}$ & $\mathrm{SD}_{8}$ & SD9 & $\mathrm{SD}_{10}$ & $\mathrm{SD}_{11}$ & $\mathrm{SD}_{12}$ & $\mathrm{SD}_{13}$ \\
\hline $\begin{array}{l}\text { Mean } \\
(\%)\end{array}$ & 0.60 & 0.74 & 0.79 & 0.40 & 0.63 & 0.54 & 0.64 & 0.31 & 0.58 & 0.99 & 0.57 & 0.50 & 0.64 \\
\hline $\begin{array}{l}\text { SDev } \\
(\%)\end{array}$ & 4.36 & 4.39 & 4.49 & 5.01 & 4.81 & 5.32 & 4.93 & 5.84 & 5.51 & 5.76 & 5.43 & 5.90 & 5.98 \\
\hline Skew & -0.50 & -0.42 & -0.97 & -1.03 & -0.55 & -0.80 & -0.40 & -0.59 & -1.05 & -0.67 & -0.54 & -0.53 & -0.18 \\
\hline Kurt & 5.39 & 5.85 & 8.17 & 8.35 & 5.36 & 6.08 & 4.32 & 5.00 & 8.05 & 6.63 & 4.94 & 6.45 & 4.95 \\
\hline $\operatorname{Min}(\%)$ & $\begin{array}{c}-20.4 \\
0\end{array}$ & $\begin{array}{c}-23.1 \\
0\end{array}$ & $\begin{array}{c}-28.9 \\
8\end{array}$ & $\begin{array}{c}-33.4 \\
8\end{array}$ & $\begin{array}{c}-25.5 \\
9\end{array}$ & $\begin{array}{c}-29.1 \\
2\end{array}$ & $\begin{array}{c}-20.1 \\
0\end{array}$ & $\begin{array}{c}-25.9 \\
8\end{array}$ & $\begin{array}{c}-32.1 \\
5\end{array}$ & $\begin{array}{c}-29.1 \\
4\end{array}$ & $\begin{array}{c}-28.4 \\
8\end{array}$ & $\begin{array}{c}-27.5 \\
2\end{array}$ & $\begin{array}{c}-27.4 \\
7\end{array}$ \\
\hline $\operatorname{Max}(\%)$ & 17.42 & 15.58 & 14.54 & 15.09 & 14.14 & 18.15 & 16.33 & 18.25 & 20.44 & 26.39 & 15.94 & 25.69 & 23.65 \\
\hline Portfolio & $\mathrm{SD}_{14}$ & $\mathrm{SD}_{15}$ & $\mathrm{SD}_{16}$ & $\mathrm{SD}_{17}$ & $\mathrm{SD}_{18}$ & $\mathrm{SD}_{19}$ & $\mathrm{SD}_{20}$ & $\mathrm{SD}_{21}$ & $\mathrm{SD}_{22}$ & $\mathrm{SD}_{23}$ & $\mathrm{SD}_{24}$ & $\mathrm{SD}_{25}$ & \\
\hline $\begin{array}{l}\text { Mean } \\
(\%)\end{array}$ & 0.69 & 0.69 & 0.32 & 0.33 & 0.76 & 0.73 & 0.71 & 0.76 & 0.38 & 0.33 & 0.55 & 0.22 & \\
\hline $\begin{array}{l}\text { SDev } \\
(\%)\end{array}$ & 6.38 & 6.21 & 6.63 & 6.84 & 6.59 & 7.46 & 7.47 & 7.39 & 7.63 & 9.30 & 8.13 & 11.06 & \\
\hline Skew & -1.00 & -0.48 & -0.43 & -0.44 & -0.47 & -0.80 & 0.07 & -0.29 & -0.23 & 0.38 & -0.07 & 0.86 & \\
\hline Kurt & 7.05 & 6.26 & 4.88 & 4.40 & 4.71 & 5.72 & 5.55 & 5.01 & 4.02 & 5.57 & 5.10 & 9.63 & \\
\hline $\operatorname{Min}(\%)$ & -37.7 & -32.4 & -31.5 & -31.3 & $\begin{array}{c}-29.1 \\
8\end{array}$ & $\begin{array}{c}-33.7 \\
2\end{array}$ & $\begin{array}{c}-33.2 \\
3\end{array}$ & -30.0 & -26.1 & $\begin{array}{c}-26.7 \\
5\end{array}$ & -29.5 & -45.0 & \\
\hline $\operatorname{Max}(\%)$ & $\begin{array}{c}0 \\
19.28\end{array}$ & 26.13 & 20.62 & 19.78 & $\begin{array}{c}0 \\
23.59\end{array}$ & 21.85 & 36.76 & 30.12 & 22.96 & 47.99 & $\begin{array}{c}4 \\
35.66\end{array}$ & 64.20 & \\
\hline
\end{tabular}

The table is divided into two panels: Panel A is for the 25 value-weighted portfolios sorted on size and book-to-market, with small to big size portfolios on the vertical side and low to high growth on the horizontal side. Panel B is for the 25 portfolios sorted on Volatility. $\mathrm{SD}_{1}$ is the portfolio with the lowest prior 12-months standard deviation and $\mathrm{SD}_{25}$ is the portfolio with the highest. Statistics reported are the Mean, Standard Deviation (SDev), Skewness (Skew), Kurtosis (Kurt), Minimum (Min), and Maximum (Max).

Table 2 displays the descriptive statistics of the risk factors, including the monthly excess returns to the market $(M K T)$ and the modified Fama-French size $(S M B)$ and value $(H M L)$ factors. $M K T$ has the highest mean of $0.52 \%$ per month with standard deviation equal to $4.5 \%$. Both $M K T$ and $H M L$ have a negative skewness with $H M L$ has the greatest Kurtosis. $S M B$ has the lowest minimum and the highest maximum.

Table 2. Summary statistics for the modified Fama and French (1993) three-factor asset pricing model risk factors

\begin{tabular}{lccc}
\hline Factors & $M K T$ & $S M B$ & $H M L$ \\
\hline Mean (\%) & 0.525 & 0.155 & 0.305 \\
SDev (\%) & 4.505 & 3.054 & 3.19 \\
Skew & -0.992 & 0.106 & -0.539 \\
Kurt & 6.652 & 5.165 & 9.49 \\
Min (\%) & -27.057 & -11.476 & -18.608 \\
Max (\%) & 13.276 & 15.607 & 12.287
\end{tabular}

Statistics reported are the Mean, Standard Deviation (SDev), Skewness (Skew), Kurtosis (Kurt), Minimum (Min), and Maximum (Max).

The correlations between the modified Fama and French (1993) three-factor asset pricing model risk factors are summarized in Table 3. It shows low correlations between the monthly excess returns to $M K T, S M B$, and $H M L$. Furthermore, the $S M B$ has a negative correlation with both the $M K T$ and $H M L$ risk factors. 
Table 3. The Correlation Coefficients between the modified Fama and French (1993) three-factor asset pricing model risk factors

\begin{tabular}{lccc}
\hline & $M K T$ & $S M B$ & $H M L$ \\
\hline$M K T$ & 1 & & \\
$S M B$ & -0.0008 & 1 & 1 \\
$H M L$ & 0.049 & -0.0591 & 1 \\
\hline
\end{tabular}

\section{Empirical Results and Analysis}

The results from the Fama and MacBeth (1973) first-stage time-series regression on the excess returns to the 25 value-weighted portfolios sorted on size and book-to-market plus 25 Volatility value-weighted portfolios are reported in Table 4. As can be shown from the table, both the MKT and the HML are statistically significant, at 5\% significance level. The rmse is equal to $0.192 \%$.

Table 4. Summary statistics for the Fama and MacBeth (1973) first-stage time-series regressions

\begin{tabular}{lcccccc}
\hline & $M K T$ & $S M B$ & $H M L$ & $r m s e(\%)$ & $F$-stat & $p$-value \\
\hline$\lambda_{T S}$ & $0.53^{*}$ & 0.15 & $0.31^{*}$ & 0.192 & 1.241 & 0.137 \\
$t$-stat & 2.3688 & 0.976 & 1.7107 & & &
\end{tabular}

The table reports the estimated factor risk premium $\left(100 * \lambda_{T S}\right)$ and its corresponding $t$-statistics $(t$-stat) as well as the root mean squared pricing errors (rmse) and its corresponding $F$-statistics ( $F$-stat) of Gibbons et al. (1989) and itsp-value. The study use one-lag Newey and West (1987) to correct for the effect of hetroskedasticity and serial correlation in the residuals. $(*)$ statistically significant at $5 \%$.

The GRS $F$-statistics shows that the null hypothesis that all pricing errors are jointly equal to zero is not rejected. The regression coefficients of the individual portfolios and its corresponding $t$-statistics are reported in Table A1 in the Appendix. The article shows a plot of actual versus predicted mean excess returns in Figure 1. The squared dots are the time-series estimated factor risk premium $\lambda_{T S}$.

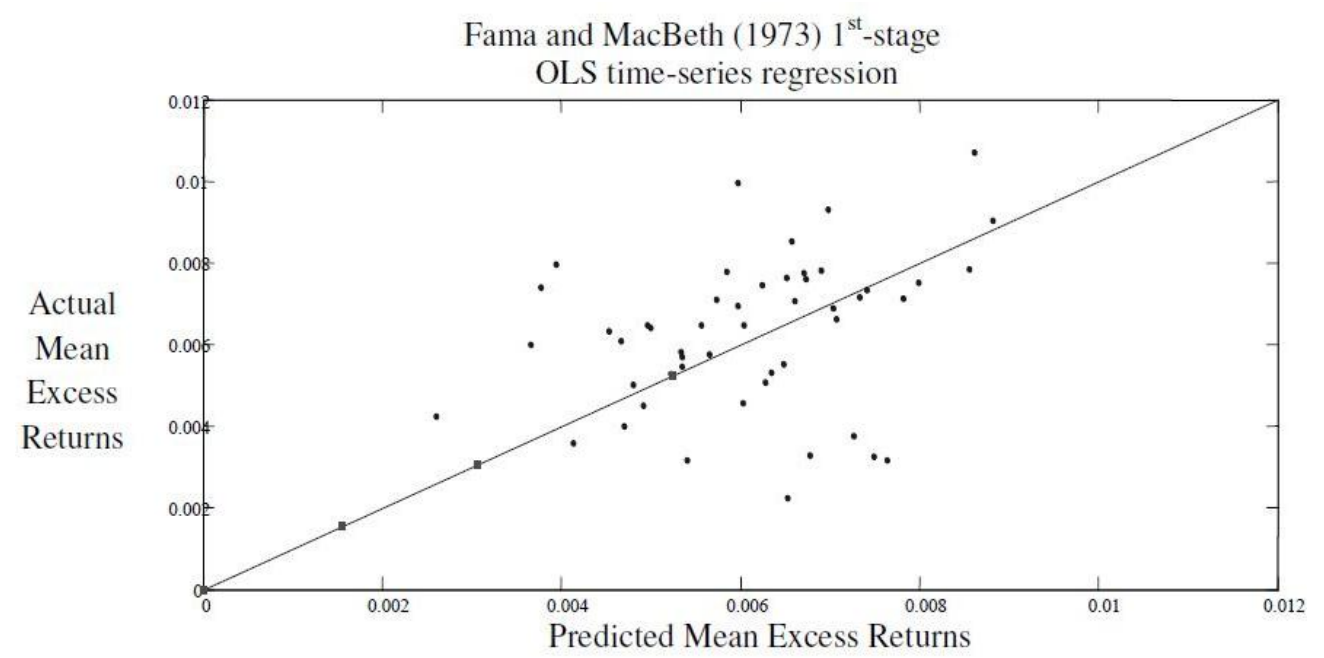

Figure 1. Actual versus predicted mean excess returns to the 25 portfolios ranked on size and book-to-market plus 25 Volatility portfolios, for the period from October 1980, to June 2015.

As can be seen from Panel A and Panel B in Table A1 and Figure 1, the null hypothesis that the pricing error $\alpha$ is equal to zero is rejected for $3 \mathrm{small} /$ growth and $1 \mathrm{big} / \mathrm{value}$, and for volatility sorted portfolio it is 4 , each out of 50. Overall, the results from the Fama and MacBeth (1973) first-stage time-series regression indicate that the modified Fama and French (1993) three-factor asset pricing model, suggested by Cremers et al. (2012), is able to explain the time-series variation in the UK equity market excess returns.

Next, the article presents the results from the Fama and MacBeth (1973) second-stage cross-sectional regression tests on the 25 value-weighted portfolios sorted on size and book-to-market plus 25 Volatility value-weighted portfolios in Table 5. To avoid the problems in the cross-sectional regression tests discussed in Shanken and Zhou (2007) and Lewellen et al. (2010), the study use the GLS approach as suggested by Lewellen et al. (2010). The results show that both the MKT 
and $H M L$ are statistically significant, at 5\% significance level. The rmse is equal to $0.193 \%$. The Shanken (1985) $F$-statistics shows that the null hypothesis that all pricing errors are jointly equal to zero is not rejected.

Table 5. Summary statistics for the Fama and MacBeth (1973) second-stage cross-sectional regression

\begin{tabular}{lcccccc}
\hline & $M K T$ & $S M B$ & $H M L$ & $r m s e(\%)$ & $F$-stat & $p$-value \\
\hline$\lambda$ & $0.58^{*}$ & 0.131 & $0.378^{*}$ & 0.192 & 1.129 & 0.265 \\
$t_{S h}$ & 2.5959 & 0.8645 & 2.3775 & & & \\
\hline
\end{tabular}

The table reports the parameter estimates $(100 * \lambda)$ and its corresponding $t$-ratio $\left(t_{S h}\right)$ of Shanken (1992) as well as the root mean squared pricing errors (rmse) and its corresponding $F$-statistics ( $F$-stat) of Shanken (1985) and its $p$-value. The test corrects for the EIV problem. The study use one-lag Newey and West (1987) to correct for the effect of hetroskedasticity and serial correlation in the residuals. $\left.{ }^{*}\right)$ statistically significant at $5 \%$.

The plot of actual versus predicted mean excess returns is in Figure 2. The squared dots are the GLS cross-sectional estimated factor risk premia $\lambda$. In contrast to Michou et al. (2007), the article finds that a modified Fama and French (1993) three-factor asset pricing model, suggested by Cremers et al. (2012), is able to explain the cross-sectional variation in the UK equity market excess returns. This is an out-of-sample evidence consistent with the Fama and French (1993) asset pricing theory.

\section{Fama and MacBeth (1973) $2^{\text {nd }}$-stage \\ GLS cross-sectional regression}

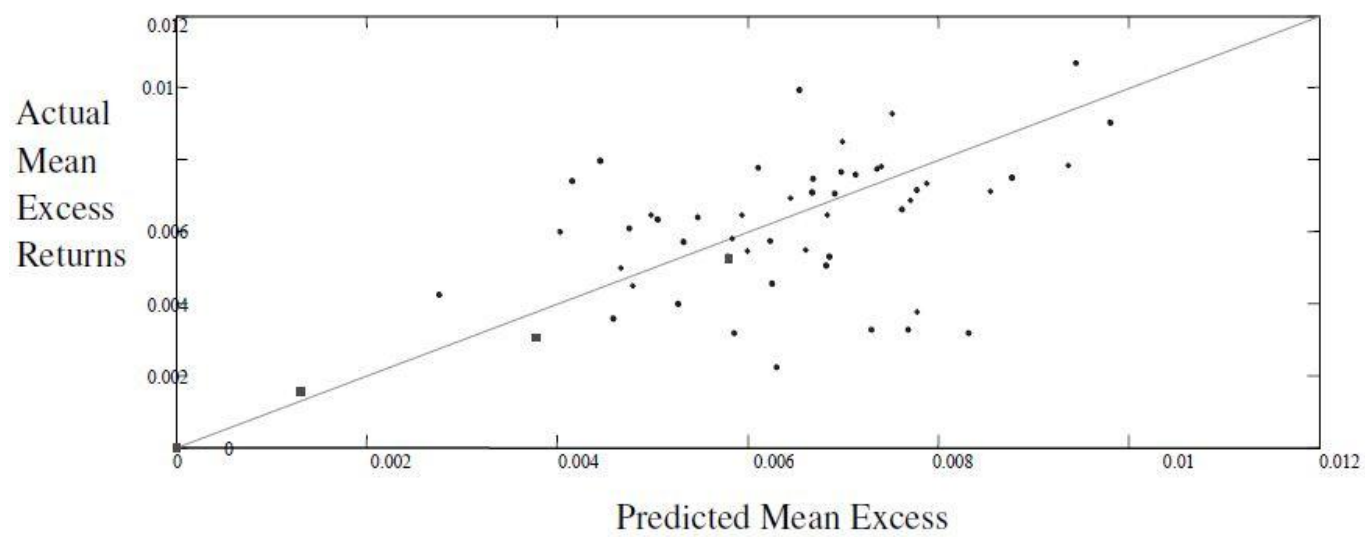

Figure 2.Actual versus predicted mean excess returns to the 25 portfolios ranked on size and book-to-market plus 25 Volatility portfolios, for the period from October, 1980, to June, 2015.

Overall, the results indicates that Gregory et al. (2013) conclusions are incorrect as they didn't apply the correct Lewellen et al. (2010) framework for examining asset pricing models. Once this is done, the study finds that a modified Fama and French(1993) three-factor asset pricing model, suggested by Cremers et al. (2012), is able to explain the cross-sectional variation in the UK equity market excess returns.

\section{Robustness}

It is reasonable to provide a robustness test using the same sample period in Gregory et al. (2013). Hence, the study considers a monthly sub-sample that ends in December 2010. The descriptive statistics of the test assets and the risk factors are in Tables 6 and 7, respectively. The article finds that descriptive statistics is not significantly affected. The correlations between the alternative factors are in Table 8. The correlation between $M K T$ and $S M B$ is now positive.

The results for the first-stage time-series regressions are presented in Table 9. The significance of the $M K T$ and $H M L$ is robust. The regression coefficients of the individual portfolios are reported in Table A2 in the Appendix. The study shows a plot of actual versus predicted mean excess returns in Figure 3.

The article notice from Panel A and Panel B in Table A2 and Figure 3, that the null hypothesis that the pricing error $\alpha$ is equal to zero is now not rejected for the $1 \mathrm{big} /$ value portfolio. 
Table 6. Summary statistics for the excess returns on the 25 value-weighted portfolios sorted on size and book-to-market plus 25 value-weighted portfolios sorted on volatility / October 1980 to December 2010.

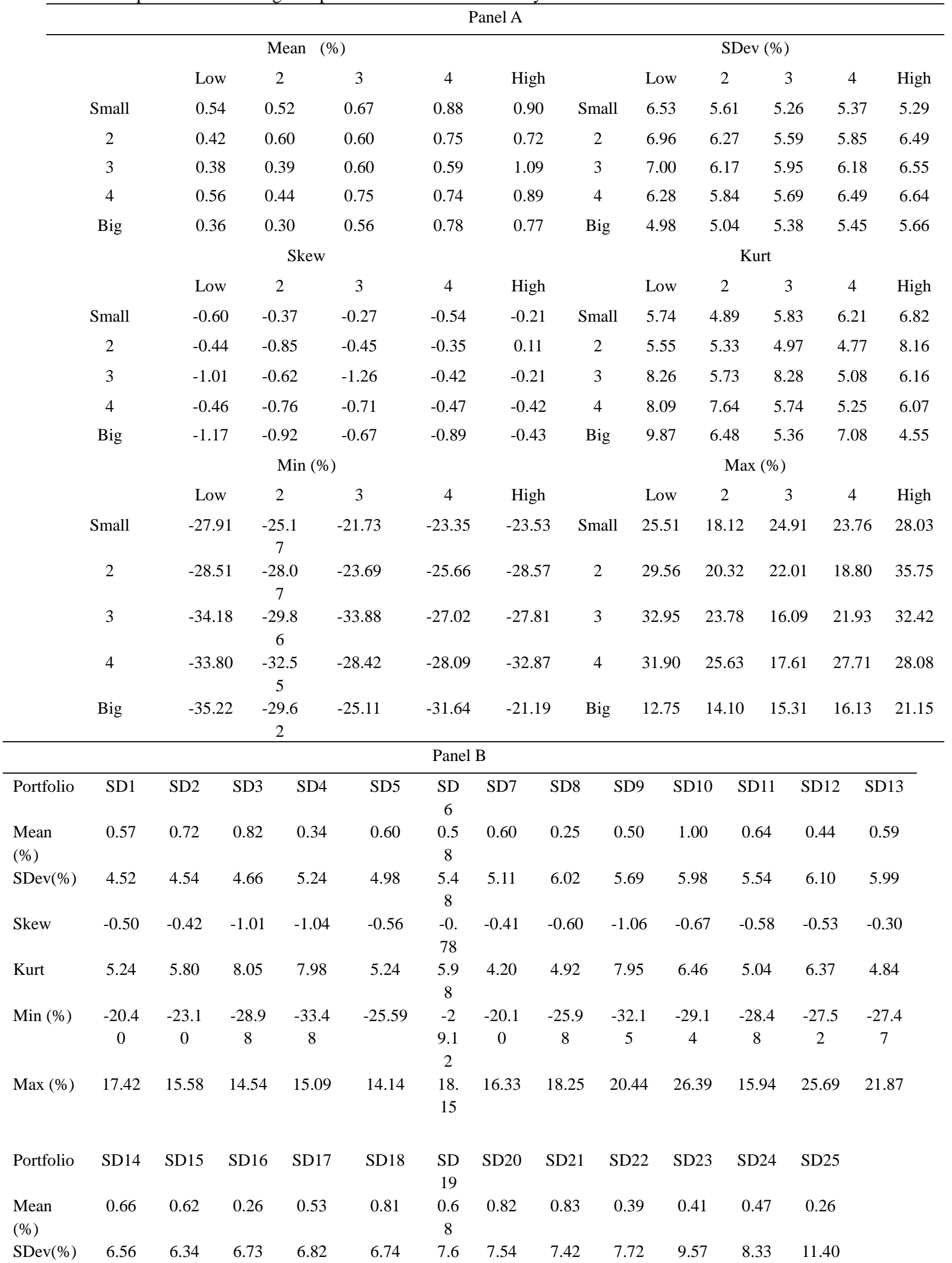




\begin{tabular}{|c|c|c|c|c|c|c|c|c|c|c|c|c|}
\hline & & & & & & 9 & & & & & & \\
\hline Skew & -1.05 & -0.46 & -0.39 & -0.48 & -0.51 & $\begin{array}{l}-0 . \\
79\end{array}$ & 0.07 & -0.42 & -0.23 & 0.41 & -0.07 & 0.90 \\
\hline Kurt & 7.09 & 6.41 & 4.75 & 4.62 & 4.79 & $\begin{array}{c}5.6 \\
0\end{array}$ & 5.65 & 5.11 & 4.05 & 5.54 & 5.11 & 9.59 \\
\hline Mini (\%) & $\begin{array}{c}-37.7 \\
6\end{array}$ & $\begin{array}{c}-32.4 \\
1\end{array}$ & $\begin{array}{c}-31.5 \\
0\end{array}$ & $\begin{array}{c}-31.3 \\
0\end{array}$ & -29.18 & $\begin{array}{c}-3 \\
3.7 \\
2\end{array}$ & $\begin{array}{c}-33.2 \\
3\end{array}$ & $\begin{array}{c}-30.0 \\
5\end{array}$ & $\begin{array}{c}-26.1 \\
1\end{array}$ & $\begin{array}{c}-26.7 \\
5\end{array}$ & $\begin{array}{c}-29.5 \\
4\end{array}$ & $\begin{array}{c}-45.0 \\
7\end{array}$ \\
\hline $\operatorname{Max}(\%)$ & 19.28 & 26.13 & 20.62 & 19.78 & 23.59 & $\begin{array}{l}21 . \\
85\end{array}$ & 36.76 & 30.12 & 22.96 & 47.99 & 35.66 & 64.20 \\
\hline
\end{tabular}

The table is divided into two panels: Panel A is for the 25 value-weighted portfolios sorted on size and book-to-market, with small to big size portfolios on the vertical side and low to high growth on the horizontal side. Panel B is for the 25 portfolios sorted on Volatility. $\mathrm{SD}_{1}$ is the portfolio with the lowest prior 12-months standard deviation and $\mathrm{SD}_{25}$ is the portfolio with the highest. Statistics reported are the Mean, Standard Deviation (SDev), Skewness (Skew), Kurtosis (Kurt), Minimum (Min), and Maximum (Max).

Table 7. Summary statistics for the modified Fama and French (1993) three-factor asset pricing model risk factors / October 1980 to December 2010.

\begin{tabular}{lccc}
\hline Factors & $M K T$ & $S M B$ & $H M L$ \\
\hline Mean (\%) & 0.51 & 0.08 & 0.39 \\
SDev (\%) & 4.67 & 3.134 & 3.315 \\
Skew & -1.00 & 0.13 & -0.60 \\
Kurt & 6.50 & 5.19 & 9.36 \\
Min (\%) & -27.05 & -11.47 & -18.60 \\
Max (\%) & 13.27 & 15.60 & 12.28
\end{tabular}

Statistics reported are the Mean, Standard Deviation (SDev), Skewness (Skew), Kurtosis (Kurt), Minimum (Min), and Maximum (Max).

Table 8. The Correlation Coefficients between the modified Fama and French (1993) three-factor asset pricing model risk factors / October 1980 to December 2010.

\begin{tabular}{lccc} 
& $M K T$ & $S M B$ & $H M L$ \\
\hline$M K T$ & 1 & & \\
$S M B$ & 0.0123 & 1 & 1 \\
$H M L$ & 0.025 & -0.0627 & 1 \\
\hline
\end{tabular}

Overall, the result that the modified Fama and French (1993) three-factor asset pricing model, suggested by Cremers et al. (2012), explains the time-series variation in the UK equity market excess returns is robust using this sub-sample.

Table 9.Summary statistics for the Fama and MacBeth (1973) first-stage time-series regressions / October 1980 to December 2010 .

\begin{tabular}{lcccccc}
\hline & $M K T$ & $S M B$ & $H M L$ & $r m s e(\%)$ & $F$-stat & $p$-value \\
\hline$\lambda_{T S}$ & $0.51^{*}$ & 0.09 & $0.39 *$ & 0.184 & 1.239 & 0.142 \\
$t$-stat & 2.0702 & 0.5004 & 1.9533 & & &
\end{tabular}

The table reports the estimated factor risk premium $\left(100^{*} \lambda_{T S}\right)$ and its corresponding $t$-statistics $(t$-stat) as well as the root mean squared pricing errors (rmse) and its corresponding $F$-statistics ( $F$-stat) of Gibbons et al. (1989) and its $p$-value. The article use one-lag Newey and West (1987) to correct for the effect of hetroskedasticity and serial correlation in the residuals. (*) statistically significant at $5 \%$. 


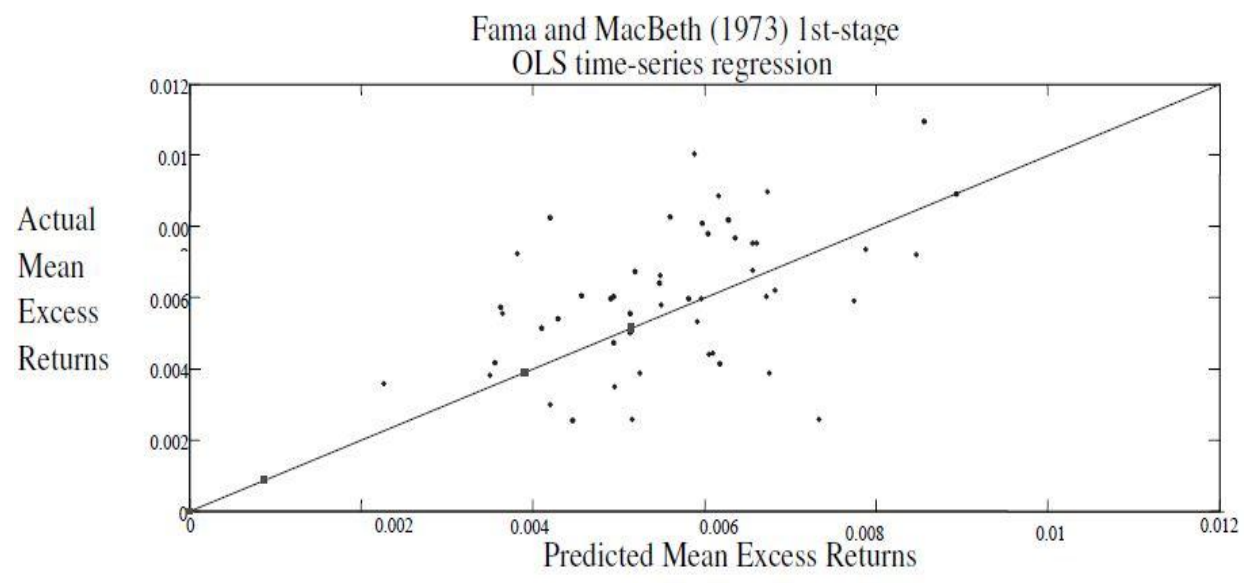

Figure 3. Actual versus predicted mean excess returns to the 25 portfolios ranked on size and book-to-market plus 25

Volatility portfolios, over the period from October 1980 to December 2010.

The results for the second-stage cross-sectional regression are in Table 10 and Figure 4 . The significance of the $M K T$ and $H M L$ is robust. The rmse is now greater by $0.029 \%$, however, the Shanken (1985) F-statistics shows that the null hypothesis that all pricing errors are jointly equal to zero is not rejected.

Table 10. Summary statistics for the Fama and MacBeth (1973) second-stage cross-sectional regression / October 1980 to December 2010.

\begin{tabular}{lcccccc}
\hline & $M K T$ & $S M B$ & $H M L$ & $r m s e(\%)$ & $F$-stat & $p$-value \\
\hline$\lambda$ & $0.572^{*}$ & 0.059 & $0.467^{*}$ & 0.183 & 1.131 & 0.265 \\
$t_{S h}$ & 2.3072 & 0.3588 & 2.6422 & & &
\end{tabular}

The table reports the parameter estimates $(100 * \lambda)$ and its corresponding $t$-ratio $\left(t_{S h}\right)$ of Shanken (1992) as well as the root mean squared pricing errors (rmse) and its corresponding $F$-statistics ( $F$-stat) of Shanken (1985) and its $p$-value. The test corrects for the EIV problem. The article use one-lag Newey and West (1987) to correct for the effect of hetroskedasticity and serial correlation in the residuals. $\left.{ }^{*}\right)$ statistically significant at $5 \%$.

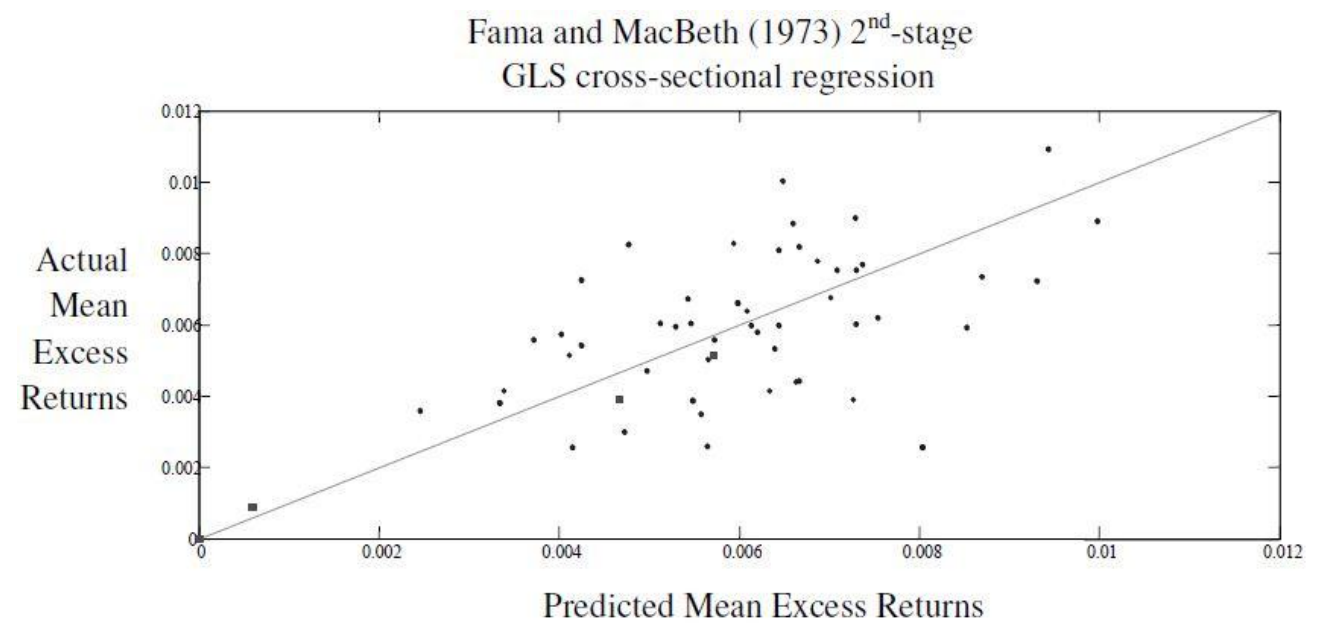

Figure 4.Actual versus predicted mean excess returns to the 25 portfolios ranked on size and book-to-market plus 25 Volatility portfolios, over the period from October 1980 to December 2010.

To briefly summarise, the result that a modified Fama and French (1993) three-factor asset pricing model, suggested by Cremers et al. (2012), explains the cross-sectional variation of the UK equity market excess returns is robust using this sub-sample period. Overall, the results suggest the use of the correct Lewellen et al (2010) for evaluating asset pricing models in the UK equity market.

\section{Conclusions}

Fama and French (1993) provided a unified general three-factor model for asset pricing. Recently, Cremers et al. (2012) 
suggest a modification to the formation of the Fama and French (1993) size and book-to-market risk factors. More Recently, Gregory et al. (2013) concerns that, compared to alternative asset pricing theories, the modified Fama and French (1993) three-factor asset pricing model is unable to explain the cross-sectional variation in the UK equity market. Using UK equity market data that covers the period from October, 1980, to June, 2015, this article shows that Gregory et al. (2013) conclusion is incorrect as they did not apply the correct Lewellen et al. (2010) framework for examining asset pricing models. Once this is done, the result suggest the use of the modified Fama and French (1993) three-factor model, suggested by Cremers et al. (2012), in practical applications that require the estimation of expected returns in the UK equity market. The result is robust using the same sample period in Gregory et al. (2013). Overall, the result suggests to apply the correct Lewellen et al. (2010) framework for evaluating asset pricing models in the UK equity market.

Acknowledgments: I am grateful to the Assistant Editor, Nikki Gibbs, and anonymous reviewers for their valuable comments and suggestions which greatly improved this article.

\section{References}

Al-Horani, A., Pope P. F., \& Andrew W. S. (2003), Research and Development Activity and Expected Returns in the United Kingdom, European Finance Review, 7(1), 27-46. http://dx.doi.org/10.1023/A:1022504029943

Black, F., Michael C. J., \& Myron S. (1972). The Capital Asset Pricing Model: Some Empirical Findings, in Michael C. Jensen, ed.: Studies in the Theory of Capital Markets (Praeger, New York).

Breeden, D. T. (1979), An Intertemporal Asset Pricing Model with Stochastic Consumption and Investment Opportunities, Journal of Financial Economics, 7(3), 165-196.http://dx.doi.org/10.1016/0304-405X(79)90016-3

Cochrane, J. H. (2005). Asset Pricing (Princeton University Press, Princeton).

Cremers, M., Antti P., \& Eric Z. (2012). Should Benchmark Indices Have Alpha? Revisiting Performance Evaluation, Critical Finance Review, 2(1), 1-48.http://dx.doi.org/10.1561/104.00000007

Daniel, K., \&Shiridan T. (2012). Testing Factor-Model Explanations of Market Anomalies, Critical Finance Review, 1(1), 103-139. http://dx.doi.org/10.1561/104.00000003

Dimson, E., Stefan N., \& Garrett Q. (2003). Capturing the Value Premium in the United Kingdom, Financial Analysts Journal, 59(6), 35-45. http://dx.doi.org/10.2469/faj.v59.n6.2573

Fama, E. F., \& James D. M. (1973). Risk, return and equilibrium: Empirical Tests, Journal of Political Economy,81(3), 607-636. http://dx.doi.org/10.1086/260061

Fama, E. F., \& Kenneth R. F. (1993). Common Risk Factors in the Returns on Stocks and Bonds, Journal of Financial Economics, 33(1), 3-56.http://dx.doi.org/10.1016/0304-405X(93)90023-5

Fama, E. F., \& Kenneth R. F. (1996). Multifactor explanations of asset pricing anomalies, Journal of Finance,51(1), 55-84. http://dx.doi.org/10.1111/j.1540-6261.1996.tb05202.x

Ferson, W. E., Sergie S., \& Timothy S. (1999).The alpha factor asset pricing model: A parable, Journal of Financial Markets, 2(1), 49-68.http://dx.doi.org/10.1016/S1386-4181(98)00005-6

Fletcher, J. (2001).An Examination of Predictable Risk and Return in UK Stock Returns, Journal of Economics and Business, 53(6), 527-46. http://dx.doi.org/10.1016/S0148-6195(01)00052-2

Fletcher, J., \& David F. (2002).An Exploration of the Persistence of UK Unit Trust Performance, Journal of Empirical Finance,9(5), 475-93. http://dx.doi.org/10.1016/S0927-5398(02)00006-3

Fletcher, J., \& Joseph K. (2005).An Examination of Alternative CAPM-based Models in UK Stock Returns, Journal of Banking and Finance, 29(12), 2995-3014.http://dx.doi.org/10.1016/j.jbankfin.2004.11.002

Gibbons, M. R., Stephan A. R., \& Jay S. (1989). A Test of the Efficiency of a Given Portfolio, Econometrica, 57(5), 1121-1152. http://dx.doi.org/10.2307/1913625

Gregory, A., Rajesh T., \& Angela C. (2013). Constructing and Testing Alternative Versions of the Fama-French and Carhart Models in the UK, Journal of Business Finance and Accounting, 40, 172-214.

Gregory, A., Richard D.F. H., \& Maria M. (2001).An Analysis of Contrarian Investment Strategies in the UK, Journal of Business Finance and Accounting,28(9\&10), 1193-1228. http://dx.doi.org/10.1111/1468-5957.00412

Hussain, S. I., Steve T., \& Steve, D. (2002). Financial Distress, Market Anomalies and Single and Multifactor Asset Pricing Models: New Evidence, working paper. http://dx.doi.org/10.2139/ssrn.313001

Lewellen, J. W., Stefan N., \& Jay, S. (2010).A Skeptical Appraisal of Asset-pricing Tests, Journal of Financial Economics, 96(2), 175-194.http://dx.doi.org/10.1016/j.jfineco.2009.09.001 
Lintner, J. (1965). The Valuation of Risk Assets and the Selection of Risky Investments in Stock Portfolios and Capital Budgets, Review of Economics and Statistics, 47(1), 13-37. http://dx.doi.org/10.2307/1924119

Liu, W., Norman S., \&Xinzhong X. (1999).The Profitability of Momentum Investing, Journal of Business Finance and Accounting, 26, 1043-1091.

Lo, A. W., \&MacKinlay A. C. (1990). Data-Snooping Biases in Tests of Financial Asset Pricing Models, Review of Financial Studies, 3(3), 431-467. http://dx.doi.org/10.1093/rfs/3.3.431

Michou, M., Sulaiman M., \& Andrew S. (2007). Estimating the Fama and French Factors in the UK: An Empirical Review, Manchester Business School, working paper.

Miles, D., \& Allan T. (1996). Variation in Expected Stock Returns: Evidence on the Pricing of Equities from a Cross-section of UK Companies, Economica, 63(251), 369-382. http://dx.doi.org/10.2307/2555012

Newey, W. K., \& Kenneth D. W. (1987). A Simple, Positive Semi-definite, Heteroskedasticity and Autocorrelation Consistent Covariance Matrix, Econometrica, 55(3), 703-708. http://dx.doi.org/10.2307/1913610

Shanken, J. (1985). Multivariate Tests of the Zero-beta CAPM, Journal of Financial Economics, 14(3), $327-348$. http://dx.doi.org/10.1016/0304-405X(85)90002-9

Shanken, J. (1992). On the Estimation of Beta-pricing Models, Review of Financial studies,5(1), 1-33.http://dx.doi.org/10.1093/rfs/5.1.1

Shanken, J., \& Guofu Z. (2007). Estimating and Testing Beta Pricing Models: Alternative Methods and Their Performance in Simulations, Journal of Financial Economics,84(1), 40-86. http://dx.doi.org/10.1016/j.jfineco.2006.02.003

Sharpe, W. F. (1964). Capital Asset Prices: A Theory of Market Equilibrium under Conditions of Risk, Journal of Finance, 19(3), 425-442. http://dx.doi.org/10.2307/2977928

\section{Appendix}

\begin{tabular}{|c|c|c|c|c|c|c|c|c|c|c|c|}
\hline \multicolumn{12}{|c|}{ Panel A } \\
\hline \multicolumn{6}{|c|}{$\alpha(\%)$} & \multicolumn{6}{|c|}{$t$-stat } \\
\hline & Low & 2 & 3 & 4 & High & & Low & 2 & 3 & 4 & High \\
\hline Small & 0.04 & 0.15 & 0.19 & 0.19 & 0.23 & Small & 0.24 & 1.13 & 1.78 & 1.90 & 2.65 \\
\hline 2 & -0.04 & 0.05 & 0.12 & 0.09 & -0.07 & 2 & -0.25 & 0.31 & 0.85 & 0.68 & -0.53 \\
\hline 3 & 0.02 & -0.15 & -0.04 & -0.07 & 0.21 & 3 & 0.14 & -1.19 & -0.33 & -0.52 & 1.51 \\
\hline 4 & 0.14 & -0.10 & 0.10 & -0.05 & 0.02 & 4 & 1.00 & -0.77 & 0.82 & -0.34 & 0.17 \\
\hline Big & 0.16 & -0.05 & 0.01 & 0.04 & 0.14 & Big & 1.72 & -0.48 & 0.06 & 0.35 & 0.95 \\
\hline \multicolumn{6}{|c|}{$b_{i, M K T}$} & \multicolumn{6}{|c|}{$t$-stat } \\
\hline & Low & 2 & 3 & 4 & High & & Low & 2 & 3 & 4 & High \\
\hline Small & 0.96 & 0.80 & 0.80 & 0.82 & 0.82 & Small & 29.11 & 27.17 & 33.15 & 36.70 & 42.77 \\
\hline 2 & 1.04 & 1.00 & 0.87 & 0.92 & 1.00 & 2 & 29.88 & 29.88 & 27.67 & 30.85 & 33.75 \\
\hline 3 & 1.09 & 1.07 & 1.04 & 1.04 & 1.05 & 3 & 33.97 & 39.68 & 36.10 & 35.13 & 34.40 \\
\hline 4 & 1.08 & 1.05 & 1.02 & 1.15 & 1.15 & 4 & 35.09 & 35.49 & 36.19 & 36.48 & 37.46 \\
\hline Big & 0.90 & 0.93 & 1.02 & 1.02 & 0.91 & Big & 42.84 & 38.10 & 38.09 & 36.89 & 28.93 \\
\hline \multicolumn{6}{|c|}{$b_{i, S M B}$} & \multicolumn{6}{|c|}{$t$-stat } \\
\hline & Low & 2 & 3 & 4 & High & & Low & 2 & 3 & 4 & High \\
\hline Small & 1.03 & 0.99 & 0.95 & 0.94 & 0.89 & Small & 21.30 & 22.85 & 26.96 & 28.24 & 31.53 \\
\hline 2 & 0.91 & 0.91 & 0.72 & 0.82 & 0.88 & 2 & 17.74 & 18.40 & 15.50 & 18.62 & 20.01 \\
\hline 3 & 0.85 & 0.75 & 0.67 & 0.65 & 0.80 & 3 & 17.87 & 18.81 & 15.88 & 14.94 & 17.79 \\
\hline 4 & 0.44 & 0.41 & 0.38 & 0.52 & 0.50 & 4 & 9.69 & 9.39 & 8.99 & 11.13 & 11.09 \\
\hline Big & -0.28 & -0.21 & -0.07 & -0.13 & -0.35 & Big & -9.19 & -5.80 & -1.69 & -3.15 & -7.55 \\
\hline \multicolumn{6}{|c|}{$b_{i, H M L}$} & \multicolumn{6}{|c|}{$t$-stat } \\
\hline & Low & $2^{\prime \prime}$ & 3 & 4 & High & & Low & 2 & 3 & 4 & High \\
\hline Small & -0.42 & -0.25 & 0.06 & 0.26 & 0.42 & Small & -8.95 & -5.92 & 1.89 & 8.29 & 15.38 \\
\hline 2 & -0.65 & -0.02 & 0.19 & 0.26 & 0.64 & 2 & -13.11 & -0.34 & 4.21 & 6.20 & 15.27 \\
\hline 3 & -0.73 & -0.25 & 0.19 & 0.44 & 0.61 & 3 & -16.12 & -6.49 & 4.72 & 10.41 & 14.22 \\
\hline 4 & -0.56 & 0.06 & 0.25 & 0.39 & 0.66 & 4 & -12.77 & 1.36 & 6.16 & 8.70 & 15.32 \\
\hline Big & -0.55 & -0.15 & -0.02 & 0.29 & 0.49 & Big & -18.48 & -4.24 & -0.43 & 7.28 & 11.02 \\
\hline
\end{tabular}




\begin{tabular}{lccccccccccccc}
\hline & \multicolumn{11}{c}{ Panel $\mathrm{B}$} \\
\hline Portfolio & $\mathrm{SD}_{1}$ & $\mathrm{SD}_{2}$ & $\mathrm{SD}_{3}$ & $\mathrm{SD}_{4}$ & $\mathrm{SD}_{5}$ & $\mathrm{SD}_{6}$ & $\mathrm{SD}_{7}$ & $\mathrm{SD}_{8}$ & $\mathrm{SD}_{9}$ & $\mathrm{SD}_{10}$ & $\mathrm{SD}_{11}$ & $\mathrm{SD}_{12}$ & $\mathrm{SD}_{13}$ \\
$\alpha(\%)$ & 0.23 & 0.36 & 0.40 & -0.07 & 0.18 & 0.01 & 0.14 & -0.22 & 0.04 & 0.39 & 0.01 & -0.12 & 0.09 \\
$t$-stat & 1.50 & 2.61 & 3.06 & -0.50 & 1.31 & 0.07 & 1.02 & -1.33 & 0.29 & 2.32 & 0.06 & -0.72 & 0.52 \\
$b_{i, M K T}$ & 0.66 & 0.75 & 0.79 & 0.91 & 0.87 & 0.93 & 0.89 & 1.06 & 0.98 & 1.00 & 0.99 & 1.03 & 1.05 \\
$t$-stat & 19.49 & 24.54 & 27.47 & 30.12 & 28.77 & 27.29 & 29.10 & 29.02 & 27.71 & 26.76 & 30.37 & 28.01 & 27.55 \\
$b_{i, S M B}$ & 0.05 & -0.02 & -0.19 & -0.14 & -0.08 & -0.05 & 0.13 & 0.13 & 0.13 & 0.24 & 0.11 & 0.36 & 0.33 \\
$t$-stat & 1.03 & -0.62 & -4.67 & -3.22 & -1.91 & -1.02 & 2.97 & 2.48 & 2.57 & 4.44 & 2.33 & 6.67 & 5.90 \\
$b_{i, H M L}$ & 0.02 & -0.04 & 0.03 & 0.03 & 0.03 & 0.16 & 0.03 & -0.12 & -0.00 & 0.10 & 0.08 & 0.08 & -0.15 \\
$t$-stat & 0.51 & -0.96 & 0.74 & 0.83 & 0.72 & 3.41 & 0.70 & -2.35 & -0.17 & 1.91 & 1.74 & 1.66 & -2.89 \\
Portfolio & $\mathrm{SD}_{14}$ & $\mathrm{SD}_{15}$ & $\mathrm{SD}_{16}$ & $\mathrm{SD}_{17}$ & $\mathrm{SD}_{18}$ & $\mathrm{SD}_{19}$ & $\mathrm{SD}_{20}$ & $\mathrm{SD}_{21}$ & $\mathrm{SD}_{22}$ & $\mathrm{SD}_{23}$ & $\mathrm{SD}_{24}$ & $\mathrm{SD}_{25}$ & \\
$\alpha(\%)$ & 0.10 & -0.01 & -0.45 & -0.35 & 0.11 & -0.01 & -0.02 & 0.09 & -0.35 & -0.42 & -0.10 & -0.43 & \\
$t$-stat & 0.51 & -0.09 & -2.42 & -1.66 & 0.58 & -0.03 & -0.08 & 0.38 & -1.39 & -1.33 & -0.36 & -1.07 & \\
$b_{i, M K T}$ & 1.12 & 1.12 & 1.14 & 1.15 & 1.13 & 1.23 & 1.23 & 1.19 & 1.20 & 1.27 & 1.15 & 1.23 & \\
$t$-stat & 26.67 & 30.40 & 28.02 & 24.75 & 26.66 & 25.04 & 25.23 & 23.04 & 21.80 & 18.30 & 19.70 & 14.02 & \\
$b_{i, S M B}$ & 0.26 & 0.36 & 0.56 & 0.46 & 0.49 & 0.71 & 0.72 & 0.59 & 0.62 & 1.13 & 1.00 & 1.50 & \\
$t$-stat & 4.14 & 6.58 & 9.29 & 6.68 & 7.74 & 9.75 & 9.92 & 7.80 & 7.64 & 10.97 & 11.61 & 11.56 & \\
$b_{i, H M L}$ & -0.10 & 0.20 & 0.27 & 0.01 & -0.06 & -0.04 & -0.08 & -0.14 & 0.00 & -0.31 & -0.36 & -0.74 & \\
$t$-stat & -1.62 & 3.90 & 4.65 & 0.19 & -1.02 & -0.65 & -1.19 & -1.97 & 0.05 & -3.14 & -4.39 & -5.94 & \\
\hline
\end{tabular}

Table A1 reports the intercept $(100 * \alpha)$ and the beta coefficient of the market factor $\left(b_{i, M K T}\right)$ and the modified Fama and French (1993) size and value factors, suggested by Cremers et al. (2012), $\left(b_{i, S M B}\right)$ and $\left(b_{i, H M L}\right)$, respectively, as well as their correspondence $t$-ratio ( $t$-stat), obtained from Fama and MacBeth (1973) first-stage time-series regressions tests of the modified Fama and French (1993) three-factor asset pricing model, on the excess returns to the 25 value-weighted portfolios formed on size and book-to-market plus 25 Volatility value-weighted portfolios, in excess of the one-month UK Treasury bill rate, as suggested by Lewellen et al. (2010), over the period from October 1980 to June 2015. The table is divided into two panels: Panel A is for the 25 value-weighted portfolios sorted on size and book-to-market, with small to big size portfolios on the vertical side and low to high growth on the horizontal side. Panel B is for the 25 portfolios sorted on Volatility. $\mathrm{SD}_{1}$ is the portfolio with the lowest prior 12-months standard deviation and $\mathrm{SD}_{25}$ is the portfolio with the highest. The article use one-lag Newey and West (1987) to correct for the effect of hetroskedasticity and serial correlation in the residuals. 


\begin{tabular}{|c|c|c|c|c|c|c|c|c|c|c|c|}
\hline \multicolumn{12}{|c|}{ Panel A } \\
\hline \multicolumn{6}{|c|}{$\alpha(\%)$} & \multicolumn{6}{|c|}{$t$-stat } \\
\hline & Low & 2 & 3 & 4 & High & & Low & 2 & 3 & 4 & High \\
\hline Small & 0.11 & 0.11 & 0.16 & 0.27 & 0.23 & Small & 0.74 & 0.77 & 1.46 & 2.51 & 2.46 \\
\hline 2 & 0.06 & 0.02 & 0.00 & 0.10 & -0.13 & 2 & 0.36 & 0.10 & 0.01 & 0.65 & -0.84 \\
\hline 3 & 0.03 & -0.14 & -0.07 & -0.18 & 0.24 & 3 & 0.19 & -1.02 & -0.49 & -1.23 & 1.57 \\
\hline 4 & 0.19 & -0.17 & 0.09 & -0.05 & 0.00 & 4 & 1.23 & -1.11 & 0.64 & -0.33 & -0.02 \\
\hline Big & 0.13 & -0.12 & 0.04 & 0.17 & 0.13 & Big & 1.23 & -0.96 & 0.33 & 1.30 & 0.82 \\
\hline \multicolumn{6}{|c|}{$b_{i, M K T}$} & \multicolumn{6}{|c|}{$t$-stat } \\
\hline & Low & 2 & 3 & 4 & High & & Low & 2 & 3 & 4 & High \\
\hline Small & 0.98 & 0.80 & 0.81 & 0.84 & 0.83 & Small & 30.49 & 27.73 & 36.01 & 37.26 & 42.62 \\
\hline 2 & 1.05 & 1.00 & 0.88 & 0.93 & 1.00 & 2 & 29.13 & 28.83 & 26.74 & 29.41 & 31.54 \\
\hline 3 & 1.10 & 1.08 & 1.04 & 1.04 & 1.05 & 3 & 31.89 & 37.79 & 34.78 & 33.17 & 32.51 \\
\hline 4 & 1.08 & 1.06 & 1.02 & 1.14 & 1.14 & 4 & 32.51 & 33.17 & 33.74 & 33.86 & 35.52 \\
\hline Big & 0.90 & 0.95 & 1.02 & 1.01 & 0.92 & Big & 39.46 & 35.83 & 35.62 & 35.55 & 27.15 \\
\hline \multicolumn{6}{|c|}{$b_{i, S M B}$} & \multicolumn{6}{|c|}{$t$-stat } \\
\hline & Low & 2 & 3 & 4 & High & & Low & 2 & 3 & 4 & High \\
\hline Small & 1.05 & 0.99 & 0.96 & 0.92 & 0.91 & Small & 21.76 & 22.99 & 28.45 & 27.33 & 31.31 \\
\hline 2 & 0.94 & 0.88 & 0.71 & 0.81 & 0.88 & 2 & 17.56 & 17.10 & 14.36 & 17.17 & 18.66 \\
\hline 3 & 0.83 & 0.74 & 0.65 & 0.64 & 0.80 & 3 & 16.02 & 17.50 & 14.50 & 13.61 & 16.55 \\
\hline 4 & 0.43 & 0.40 & 0.38 & 0.52 & 0.50 & 4 & 8.64 & 8.48 & 8.36 & 10.33 & 10.48 \\
\hline Big & -0.29 & -0.21 & -0.05 & -0.15 & -0.35 & Big & -8.47 & -5.32 & -1.11 & -3.54 & -6.99 \\
\hline \multicolumn{6}{|c|}{$b_{i, H M L}$} & \multicolumn{6}{|c|}{$t$-stat } \\
\hline & Low & 2 & 3 & 4 & High & & Low & 2 & 3 & 4 & High \\
\hline Small & -0.43 & -0.23 & 0.04 & 0.26 & 0.43 & Small & -9.43 & -5.67 & 1.41 & 8.16 & 15.79 \\
\hline 2 & -0.68 & -0.03 & 0.20 & 0.27 & 0.66 & 2 & -13.39 & -0.52 & 4.38 & 6.06 & 14.67 \\
\hline 3 & -0.74 & -0.24 & 0.21 & 0.46 & 0.63 & 3 & -15.16 & -5.96 & 4.88 & 10.44 & 13.93 \\
\hline 4 & -0.58 & 0.08 & 0.26 & 0.40 & 0.68 & 4 & -12.39 & 1.82 & 6.10 & 8.29 & 15.03 \\
\hline Big & -0.54 & -0.12 & -0.01 & 0.25 & 0.49 & Big & -16.71 & -3.31 & -0.37 & 6.28 & 10.23 \\
\hline
\end{tabular}

\section{Panel B}

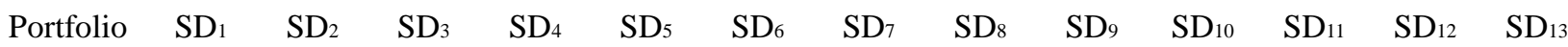

$\begin{array}{lcccccccccccccc}\alpha(\%) & 0.21 & 0.34 & 0.40 & -0.14 & 0.14 & 0.03 & 0.10 & -0.25 & -0.01 & 0.41 & 0.09 & -0.16 & 0.10 \\ t \text {-stat } & 1.20 & 2.26 & 2.79 & -0.95 & 0.97 & 0.18 & 0.71 & -1.41 & -0.06 & 2.20 & 0.57 & -0.89 & 0.59 \\ b_{i, M K T} & 0.66 & 0.75 & 0.79 & 0.93 & 0.86 & 0.94 & 0.89 & 1.05 & 0.97 & 1.01 & 0.98 & 1.03 & 1.03 \\ t \text {-stat } & 17.80 & 23.65 & 26.03 & 28.72 & 26.80 & 26.09 & 27.65 & 27.70 & 25.86 & 25.33 & 28.63 & 26.52 & 27.16 \\ b_{i, S M B} & 0.07 & -0.00 & -0.17 & -0.13 & -0.06 & -0.07 & 0.13 & 0.14 & 0.13 & 0.26 & 0.10 & 0.38 & 0.31 \\ t \text {-stat } & 1.40 & -0.07 & -3.73 & -2.75 & -1.38 & -1.45 & 2.77 & 2.51 & 2.30 & 4.40 & 1.98 & 6.50 & 5.48 \\ b_{i, H M L} & 0.04 & -0.01 & 0.06 & 0.07 & 0.04 & 0.18 & 0.05 & -0.10 & -0.00 & 0.11 & 0.08 & 0.09 & -0.17 \\ t \text {-stat } & 0.79 & -0.43 & 1.43 & 1.53 & 0.87 & 3.64 & 1.15 & -1.98 & -0.08 & 2.06 & 1.68 & 1.78 & -3.20\end{array}$

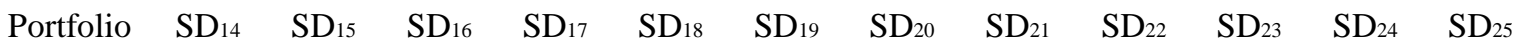

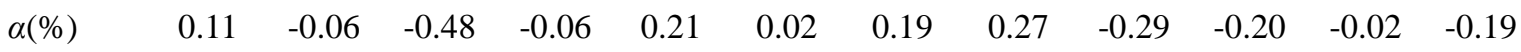




$\begin{array}{lcccccccccccc}t \text {-stat } & 0.55 & -0.34 & -2.43 & -0.27 & 1.05 & 0.08 & 0.81 & 1.08 & -1.10 & -0.59 & -0.08 & -0.44 \\ b_{i, M K T} & 1.11 & 1.11 & 1.12 & 1.11 & 1.14 & 1.22 & 1.20 & 1.15 & 1.19 & 1.26 & 1.11 & 1.20 \\ t \text {-stat } & 25.18 & 28.96 & 26.98 & 23.75 & 26.82 & 23.23 & 24.03 & 21.92 & 21.62 & 17.39 & 18.26 & 13.05 \\ b_{i, S M B} & 0.23 & 0.34 & 0.57 & 0.46 & 0.48 & 0.70 & 0.76 & 0.60 & 0.69 & 1.15 & 1.03 & 1.52 \\ t \text {-stat } & 3.48 & 5.88 & 9.11 & 6.64 & 7.62 & 8.91 & 10.18 & 7.61 & 8.36 & 10.63 & 11.35 & 11.03 \\ b_{i, H M L} & -0.11 & 0.21 & 0.27 & -0.05 & -0.08 & -0.08 & -0.13 & -0.22 & 0.01 & -0.34 & -0.43 & -0.78 \\ t \text {-stat } & -1.79 & 3.95 & 4.69 & -0.79 & -1.41 & -1.08 & -1.92 & -2.94 & 0.15 & -3.32 & -5.00 & -6.01\end{array}$

Table A2 reports the intercept $(100 * \alpha)$ and the beta coefficient of the market factor $\left(b_{i, M K T}\right)$ and the modified Fama and French (1993) size and value factors, suggested by Cremers et al. (2012), $\left(b_{i, S M B}\right)$ and $\left(b_{i, H M L}\right)$, respectively, as well as their correspondence t-ratio (t-stat), obtained from Fama and MacBeth (1973) first-stage time-series regressions tests of the modified Fama and French (1993) three-factor asset pricing model, on the excess returns to the 25 value-weighted portfolios formed on size and book-to-market plus 25 Volatility value-weighted portfolios, in excess of the one-month UK Treasury bill rate, as suggested by Lewellen et al. (2010),over the period from October 1980 to December 2010. The table is divided into two panels: Panel A is for the 25 value-weighted portfolios sorted on size and book-to-market, with small to big size portfolios on the vertical side and low to high growth on the horizontal side. Panel B is for the 25 portfolios sorted on Volatility. SD1 is the portfolio with the lowest prior 12-months standard deviation and SD25 is the portfolio with the highest. The article use one-lag Newey and West (1987) to correct for the effect of hetroskedasticity and serial correlation in the residuals.

\section{(c) $)$ EY}

This work is licensed under a Creative Commons Attribution 3.0 License.

\footnotetext{
${ }^{\mathrm{i}}$ Severalstudies provide evidence for the profitability of value strategies in the UK, such as Gregory et al. (2001) and Dimson et al. (2003).

ii They also use the SMB and HML in Fletcher (2001), Fletcher and Forbes (2002) and Fletcher and Kihanda (2005) who examine the adequacy of various benchmark specifications, including the Fama and French (1993) three factor asset pricing model, in UK trust performance evaluation

iii Specifically, they argue that the Fama and French (1993) approach in which the two components they use in constructing each of the SMB and the HML are equally-weighted returns gives a disproportionate weight to small value stocks. Instead, they suggest constructing each of the SMB and the HML using value-weighted returns, i.e. based on the market capitalization of the six portfolios used in constructing the factors.

iv Shanken and Zhou (2007) compare the statistical properties of the OLS and the GLS approaches of the Fama-MacBeth beta procedure, under the non-normality assumption, using the CAPM and the Fama and French (1993) three-factor asset pricing model, and find that the GLS is more precise than the OLS.

$\checkmark$ Their work is built on the work of Ferson et al. (1999) and Daniel and Titman (2005) who argue that asset pricing tests should be more strict.

vi The article use Volatility sorted portfolios to avoid difficulties caused by certain industry changes in the UK. According to Gregory et al. (2013), the privatizations of utilities and the rail industry have led to the emergence of significant new sectors. These changes are essentially the result of political choices.

vii All estimates and test statistics are obtained using Matlab.

viii http://business-school.exeter.ac.uk/research/areas/centres/xfi/research/famafrench/files/

ix Dividend payments are included.
} 